\title{
Simulation Based Analytical Investigation of Multi-phase Induction Machine in Motoring and Generating Mode
}

\author{
Alok Kumar Mohanty ${ }^{\# 1}$, K B Yadav ${ }^{* 2}$ \\ ${ }^{\#}$ Department of Electrical and Electronics Engineering, National Institute of Technology, Jamshedpur, India \\ 1.alokmoh@gmail.com \\ * Department of Electrical and Electronics Engineering, National Institute of Technology, Jamshedpur, India \\ 2 yadavbkrishna@rediffmail.com
}

\begin{abstract}
Multi-phase variable speed machines are now-a-days considered advantageous as compared to three phase counterpart for various applications either operating in motoring mode or generating mode. The modeling and analysis of a multi-phase (six-phase) machine when operating in motoring and generating mode have been presented in this paper. In motoring mode the model is simulated to evaluate its performance under load and no-load conditions which includes current, torque and speed characteristics. During generating mode of operation the simulations were carried out and evaluations were made on the basis of the machine behavior which includes voltage and current behavior during noload period and when subjected to load. Simulation results are provided to confirm the ability of these models to represent during no load as well as during load period and the result were found to be satisfactory.
\end{abstract}

Keywords: Multi-phase; Induction machine; Motor; Generator; Analysis

\section{INTRODUCTION}

A greater degree of freedom is achieved in electrical drives system when phases of machine are changed with one having greater number of phase. For applications where reliability is very important, application of multi-phase machine has emerged as a very feasible option. During faulty conditions in one or more stator phases, a multi-phase induction machine can continue to be operated with an appropriate post-fault strategy $[1,2,, 3]$. Then, reducing the torque oscillations presented in drives with three-phase machines powered by six-step inverters. Among other reasons, the fault tolerance is the most important. Now-a-days, the multiphase machines can be used in high and low power applications.

The analytical modeling of a multi-phase induction machine (six phase) operating in motoring as well as in generating mode has been implemented in this paper and the analysis of the machine has been carried out with symmetrical phase displacement between the six stator windings. The mathematical model is implemented for motor as well as the generator under load and no-load conditions. In motoring mode the model is simulated to evaluate its performance under load and no-load conditions which includes current, torque and speed characteristics. During generating mode of operation the simulations were carried out and evaluations were made on the basis of the machine behavior which includes voltage and current behavior during no-load period and when subjected to load. Simulation results are provided to confirm the ability of these models to represent during no load as well as during load period.

\section{Multi-PHASE MAChines}

Machines having phases more than three in comparison with conventional machine are termed as a high phase order machine or multi-phase machines. Multi-phase machines have certain advantages when compared with its three phase counterpart such as ability to start and run when one or two stator phases are short or open, lesser current in phase, increment in power[3]. Basically a multi-phase induction machine can have two different types of configurations namely split phase electrical machines and dual stator electrical machines.

In a conventional three phase machine ,the conductors are distributed in slots symmetrically for each phase group and the conductors belonging to each phase group are series whereas in a multiphase induction machine we subdivide each phase group of a usual three phase machine into equal subgroups by disconnecting the series connection of the conductors. More number of three phase groups can be obtained from the same machine. In this way multiphase machine such as six phases, nine phases, twelve phases, fifteen phases and eighteen phases can be produced from a three phase machine by subdividing the phase groups into two, three, four subgroups respectively. 


\section{III.SIX-PHASE INDUCTION MOTOR MODELING}

The machine considered for analysis has a stator which consists of six-phases consisting of two sets are (with phase shift between phases of $120^{\circ}$ ) separated by an angle $\alpha$. This angle can take values such as $0^{\circ}, 30^{\circ}$ and $60^{\circ}$. In this study, the rotor is considered equivalent to a three-phase winding $[3,4,5,6]$. There is no core loss and magnetic saturation in the core. There is no friction and windage loss in the system.

A induction machine operating in six phase mode has two stator winding sets namely 123 and xyz, whose axes are separated by $\alpha$ [7-12]. The three-phase set are distributed and the axes are displaced $120^{\circ}$ apart from each other. The rotor windings ar, br, cr as shown in Figure 2 is distributed in sinusoidal manner and has separation of $120^{\circ}$.

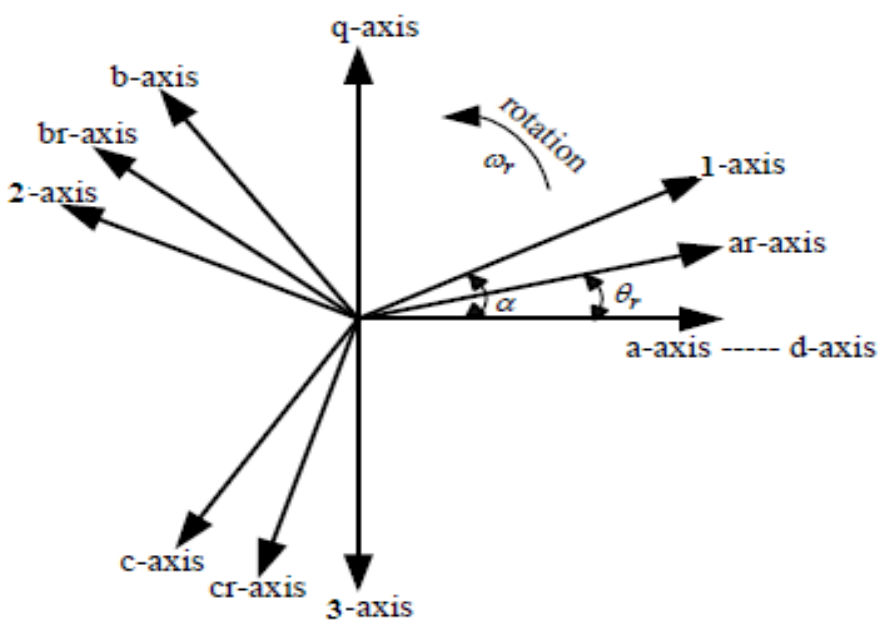

Fig.1.Phasor diagram representation multi-phase induction machine

\section{(A) Voltage equations}

The voltage equations of the machine during motoring mode are as follows:

$v_{q 1}=r_{1} i_{q 1}+\omega_{k} \lambda_{d 1}+p \lambda_{q 1}$
$v_{d 1}=r_{1} i_{d 1}-\omega_{k} \lambda_{q 1}+p \lambda_{d 1}$
$v_{q 2}=r_{2} i_{q 2}+\omega_{k} \lambda_{d 2}+p \lambda_{q 2}$
$v_{d 2}=r_{2} i_{d 2}-\omega_{k} \lambda_{q 2}+p \lambda_{d 2}$
$v_{q r}=r_{r} i_{q r}+\omega_{k} \lambda_{d r}-\omega_{r} \lambda_{d r}+p \lambda_{q r}=0$
$v_{d r}=r_{r} i_{d r}-\omega_{k} \lambda_{q r}+\omega_{r} \lambda_{q r}+p \lambda_{d r}=0$

(B)Flux linkage equations

The equations that represent the flux linkages of the machine are represented as follows

$\lambda_{q 1}=L_{l 1} i_{q 1}+L_{m q} i_{q 1}+L_{m q} i_{q 2}+L_{m q} i_{q r}+L_{l m} i_{q 1}+L_{l m} i_{q 2}+L_{d q} i_{d 2}$

$\lambda_{d 1}=L_{l 1} i_{d 1}+L_{m d} i_{d 1}+L_{m d} i_{d 2}+L_{m d} i_{d r}+L_{l m} i_{d 1}+L_{l m} i_{d 2}+L_{d q} i_{q 2}$

$\lambda_{q 2}=L_{l 2} i_{q 2}+L_{m q} i_{q 1}+L_{m q} i_{q 2}+L_{m q} i_{q r}+L_{l m} i_{q 1}+L_{l m} i_{q 2}+L_{d q} i_{d 1}$

$\lambda_{d 2}=L_{l 2} i_{d 1}+L_{m d} i_{d 1}+L_{m d} i_{d 2}+L_{m d} i_{d r}+L_{l m} i_{d 1}+L_{l m} i_{d 2}+L_{d q} i_{q 1}$

$\lambda_{q r}=L_{l r} i_{q r}+L_{m q} i_{q 1}+L_{m q} i_{q 2}+L_{m q} i_{q r}$

$\lambda_{d r}=L_{l r} i_{d r}+L_{m d} i_{q 1}+L_{m d} i_{q 2}+L_{m d} i_{q r}$

If we assume $L_{d q}=0$

$L_{m}=L_{m q}=L_{m d}$

$L_{1}=L_{l 1}+L_{l m}+L_{m}$

$L_{2}=L_{l 2}+L_{l m}+L_{m}$

$L_{3}=L_{l m}+L_{m}$

$L_{r}=L_{l r}+L_{m}$

Substituting (13-18) in eqn. (7-12)

$\lambda_{q 1}=L_{1} i_{q 1}+L_{3} i_{q 2}+L_{m} i_{q r}$ 
$\lambda_{d 1}=L_{1} i_{d 1}+L_{3} i_{d 2}+L_{m} i_{d r}$

$\lambda_{q 2}=L_{2} i_{q 1}+L_{3} i_{q 2}+L_{m} i_{q r}$

$\lambda_{d 2}=L_{2} i_{d 1}+L_{3} i_{d 2}+L_{m} i_{d r}$

$\lambda_{q r}=L_{r} i_{q r}+L_{m} i_{q 1}+L_{m} i_{q 2}$

$\lambda_{d r}=L_{r} i_{d r}+L_{m} i_{d 1}+L_{m} i_{d 2}$

The electromagnetic torque expression is given by

$T_{e}=(3 / 2)(P / 2)\left[\lambda_{m d} i_{q 1}+\lambda_{m d} i_{q 2}-\lambda_{m q} i_{d 1}-\lambda_{m q} i_{d 2}\right]$

\section{IV.SIX-PHASE INDUCTION GENERATOR MODELING}

The equations for the self excited induction generator operating in six phase mode, describes the behavior of a multi-phase machine, it is assumed that the neutral of both the stator winding sets are separate so that if a fault occurs in one set of the stator windings it does not propagate to the other set. The following voltage equations are written for a multi- phase induction machine as shown in equivalent circuit of the machine in Fig.2.

For the development of model of the six-phase machine operating in generating mode the following differential equations are derived from the equivalent circuit of the machine. In the equivalent circuit applying KVL equations we get the following voltage equations.

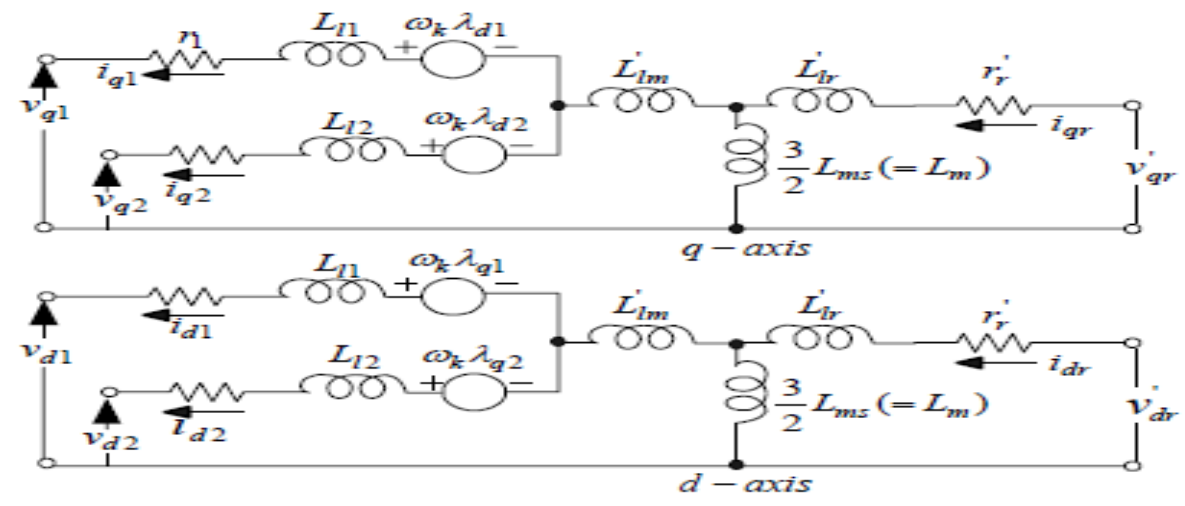

Fig.2.Circuit representation of induction generator for six phase operation

(A)Voltage equations

$$
\begin{aligned}
& v_{d 1}=-r_{1} i_{d 1}+\omega_{k} \lambda_{d 1}+\frac{d}{d t} \lambda_{d 1} \\
& v_{q 1}=-r_{1} i_{q 1}+\omega_{k} \lambda_{q 1}+\frac{d}{d t} \lambda_{q 1} \\
& v_{d 2}=-r_{2} i_{d 2}+\omega_{k} \lambda_{d 2}+\frac{d}{d t} \lambda_{d 2} \\
& v_{q 2}=-r_{2} i_{q 2}+\omega_{k} \lambda_{q 2}+\frac{d}{d t} \lambda_{q 2} \\
& 0=r_{r} i_{d r}-\omega_{k} \lambda_{q r}+\omega_{r} \lambda_{q r}+\frac{d}{d t} \lambda_{d r} \\
& 0=r_{r} i_{q r}+\omega_{k} \lambda_{d r}-\omega_{r} \lambda_{d r}+\frac{d}{d t} \lambda_{q r}
\end{aligned}
$$

Where $\omega_{k}$ is the reference frame speed, $\omega_{r}$ is the rotor speed. In this analysis the rotor quantities are referred to stator.

The flux linkage expressions in terms of currents obtained from the equivalent circuit.

(B)Flux linkages equations

$\lambda_{d 1}=L_{11} i_{d 1}-L_{l m} i_{d 1}-L_{l m} i_{d 2}+L_{m} i_{d r}-L_{m} i_{d 1}-L_{m} i_{d 2}$

$\lambda_{q 1}=-L_{11} i_{q 1}-L_{l m} i_{q 1}-L_{l m} i_{q 2}+L_{m} i_{q r}-L_{m} i_{q 1}-L_{m} i_{q 2}$

$\lambda_{d 2}=-L_{12} i_{q 2}-L_{l m} i_{d 1}-L_{l m} i_{d 2}+L_{m} i_{d r}-L_{m} i_{d 1}-L_{m} i_{d 2}$

$\lambda_{q 2}=-L_{12} i_{q 2}-L_{l m} i_{q 1}-L_{l m} i_{q 2}+L_{m} i_{q r}-L_{m} i_{q 1}-L_{m} i_{q 2}$

$\lambda_{d r}=L_{l r} i_{d r}+L_{m} i_{d r}-L_{m} i_{d 1}-L_{m} i_{d 2}$

$\lambda_{q r}=L_{l r} i_{q r}+L_{m} i_{q r}-L_{m} i_{q 1}-L_{m} i_{q 2}$ 
Solving this equations (17-22) for obtaining current equations

$$
\begin{aligned}
& i_{d 1}=\frac{1}{L_{l}}\left[L_{l m} \lambda_{d 1}+L_{12} \lambda_{d 1}-L_{l m} \lambda_{d 2}-L_{12} \lambda_{m d}\right] \\
& i_{q 1}=\frac{1}{L_{l}}\left[L_{l m} \lambda_{q 1}+L_{12} \lambda_{q 1}-L_{l m} \lambda_{q 2}-L_{12} \lambda_{m q}\right] \\
& i_{d 2}=\frac{1}{L_{l}}\left[L_{l m} \lambda_{d 2}+L_{12} \lambda_{d 2}-L_{l m} \lambda_{d 1}-L_{12} \lambda_{m d}\right] \\
& i_{q 1}=\frac{1}{L_{l}}\left[L_{l m} \lambda_{q 2}+L_{12} \lambda_{q 2}-L_{l m} \lambda_{q 1}-L_{12} \lambda_{m q}\right] \\
& i_{d r}=\left[\frac{\lambda_{d r}}{L_{l r}}-\frac{\lambda_{m d}}{L_{l r}}\right] \\
& i_{q r}=\left[\frac{\lambda_{q r}}{L_{l r}}-\frac{\lambda_{m q}}{L_{l r}}\right]
\end{aligned}
$$

Substituting the values of the currents obtained in the equation (38) to (43) in the voltage equations (26) to (31) the following expressions are obtained.

$$
\begin{aligned}
& \lambda_{d 1}=\left\{\left\{v_{d 1}-\frac{r_{1}}{L_{l}} L_{l m} \lambda_{d 1}-\frac{r_{1}}{L_{l}} L_{12} \lambda_{d 1}+\frac{r_{1}}{L_{l}} L_{l m} \lambda_{d 2}+\frac{r_{1}}{L_{l}} L_{12} \lambda_{m d}-\Phi_{k} \lambda_{q 1}\right\}\right. \\
& \lambda_{q 1}=\int\left\{v_{q 1}-\frac{r_{1}}{L_{l}} L_{l m} \lambda_{q 1}-\frac{r_{1}}{L_{l}} L_{12} \lambda_{q 1}+\frac{r_{1}}{L_{l}} L_{l m} \lambda_{q 2}+\frac{r_{1}}{L_{l}} L_{12} \lambda_{m q}+\varpi_{k} \lambda_{d 1}\right\} \\
& \lambda_{d 2}=\int\left\{v_{d 2}-\frac{r_{1}}{L_{l}} L_{l m} \lambda_{d 2}-\frac{r_{2}}{L_{l}} L_{11} \lambda_{d 2}+\frac{r_{1}}{L_{l}} L_{l m} \lambda_{d 1}+\frac{r_{1}}{L_{l}} L_{12} 1-\Phi_{k} \lambda_{q 1}\right\} \\
& \lambda_{q 2}=\int\left\{v_{q 2}-\frac{r_{1}}{L_{l}} L_{l m} \lambda_{q 2}-\frac{r_{2}}{L_{l}} L_{11} \lambda_{q 2}+\frac{r_{1}}{L_{l}} L_{l m} \lambda_{q 1}+\frac{r_{1}}{L_{l}} L_{11} \lambda_{m q}+\Phi_{k} \lambda_{d 2}\right\} \\
& \lambda_{d r}=\left\{\left\{\omega_{k} \lambda_{q r}-\omega_{r} \lambda_{q r}-\frac{r_{r}}{L_{l r}} \lambda_{d r}+\frac{r_{r}}{L_{l r}} \lambda_{m d}\right\}\right. \\
& \lambda_{q r}=\left\{\left\{-\omega_{k} \lambda_{d r}+\omega_{r} \lambda_{d r}-\frac{r_{r}}{L_{l r}} \lambda_{q r}+\frac{r_{r}}{L_{l r}} \lambda_{m q}\right\}\right. \\
& \lambda_{m d}=A\left[\frac{L_{12} \lambda_{d 1}+L_{11} \lambda_{d 2}}{L}+\frac{\lambda_{m d}}{L_{l r}}\right] \\
& \lambda_{m q}=A\left[\frac{L_{12} \lambda_{q 1}+L_{11} \lambda_{q 2}}{L}+\frac{\lambda_{m q}}{L_{l r}}\right] \\
& L=\left[L_{11} L_{12}+L_{l m} L_{11}+L_{l m} L_{12}\right] \\
& A=1 /\left[\left(1 / L_{m}\right)+\left(1 / L_{l r}\right)+\left(L_{l 1}+L_{l 2} / L\right)\right]
\end{aligned}
$$

The torque can be computed as a function of $\mathrm{q}$ and $\mathrm{d}$ axes stator and rotor currents

$T_{m}=(P / 2)(3 / 2)\left(L_{m} / L_{r}\right)\left[i_{q 1} \lambda_{d r}+i_{q 2} \lambda_{d r}-i_{d 1} \lambda_{q r}-i_{d 2} \lambda_{q r}\right]$

The rotor equation is expressed as

$\omega_{r}=\int\left(T_{m}-T_{s}\right)(1 / J)(P / 2)$

Where $J$ is moment of inertia, $P$ is is the number of poles, $T_{S}$ is the shaft torque.

$L_{l r}+L_{m}=L_{r}$

The magnetizing inductance $L_{m}$ is not a constant but a function which depends on the instantaneous value of magnetizing current $i_{m}$ given by $L_{m}=$ function $\left(i_{m}\right)$. During simulation, in each step, the magnetizing inductance $L_{m}$ is updated as a function of the magnetizing current $i_{m}$.

$i_{m}=\sqrt{\left(i_{q r}-i_{q 1}-i_{q 2}\right)^{2}+\left(i_{d r}-i_{d 1}-i_{d 2}\right)^{2}}$

The magnetizing inductance $L_{m}$ is calculated from the magnetizing characteristics fourth order polynomial for the test machine $i_{m}$. The 4 th order polynomial is arrived at, by applying curve fit technique to the relationship between $L_{m}$ and $i_{m}$,obtained by performing synchronous speed test on the test induction machine.

$L_{m}=x_{0}+x_{1} i_{m}+x_{2} i_{m}{ }^{2}+x_{3} i_{m}{ }^{3}$

Where $x_{0}, x_{1} \cdot x_{2}, x_{3}$ are constants values

The torque balance equation is expressed as the derivative of the speed

$\frac{d_{\Phi r}}{d t}=\left(\frac{P}{2 J}\right)\left(T_{m}-T_{s}\right)$

\section{(C) Shunt Capacitor for excitation}

The excitation system of the six-phase machine introduces the following state equations which uses dq components of the stator voltages as state variables in the equivalent circuit.

$\frac{d}{d t} v_{d 1}=\left(i_{d 1} / c_{1}\right)-\left(i_{l d 1} / c_{1}\right)$ 
$\frac{d}{d t} v_{q 1}=\left(i_{q 1} / c_{1}\right)-\left(i_{l q 1} / c_{1}\right)$

$\frac{d}{d t} v_{d 2}=\left(i_{d 2} / c_{2}\right)-\left(i_{l d 2} / c_{1}\right)$

$\frac{d}{d t} v_{q 2}=\left(i_{q 2} / c_{2}\right)-\left(i_{l q 2} / c_{1}\right)$

(d) Load impedances

An induction generator is made self-excited by providing the magnetizing reactive power provided by the capacitor bank. The current expressions for balanced resistive load can be expressed as

$i_{d=\frac{V_{d}}{R}}$
$i_{q=\frac{V q}{R}}$

Where $\mathrm{R}$ is the resistive load

The load impedance model for RLC load expressed in arbitrary reference frame is as follows

$i_{l d 1}=\left(\int\left(\frac{v_{l d 1}}{L_{1}}\right)-\left(\frac{R_{1} i_{l d 1}}{L_{1}}\right)-\frac{1}{L_{1} c_{1}} \int i_{l d 1}\right)$
$i_{l q 1}=\left(\int\left(\frac{v_{l q 1}}{L_{1}}\right)-\left(\frac{R_{1} i_{l q 1}}{L_{1}}\right)-\frac{1}{L_{1} c_{1}} \int i_{l q 1}\right)$
$i_{l d 2}=\left(\int\left(\frac{v_{l d 2}}{L_{2}}\right)-\left(\frac{R_{2} i_{l d 2}}{L_{2}}\right)-\frac{1}{L_{1} c_{1}} \int i_{l d 2}\right)$
$i_{l q 1}=\left(\int\left(\frac{v_{l q 2}}{L_{2}}\right)-\left(\frac{R_{1} i_{l q 2}}{L_{2}}\right)-\frac{1}{L_{1} c_{1}} \int i_{l q 2}\right)$

\section{(A)Six-phase induction machine operating in motoring mode}

The model of the six-phase induction machine operating in motoring mode to be analyzed was simulated with two different sources, first with a direct ac start up and secondly as an inverter fed machine. The simulation was carried out in MATLAB/Simulink environment. The complete simulink models of the machine being fed with two different sources are shown in Fig. 3 \& 4 respectively.

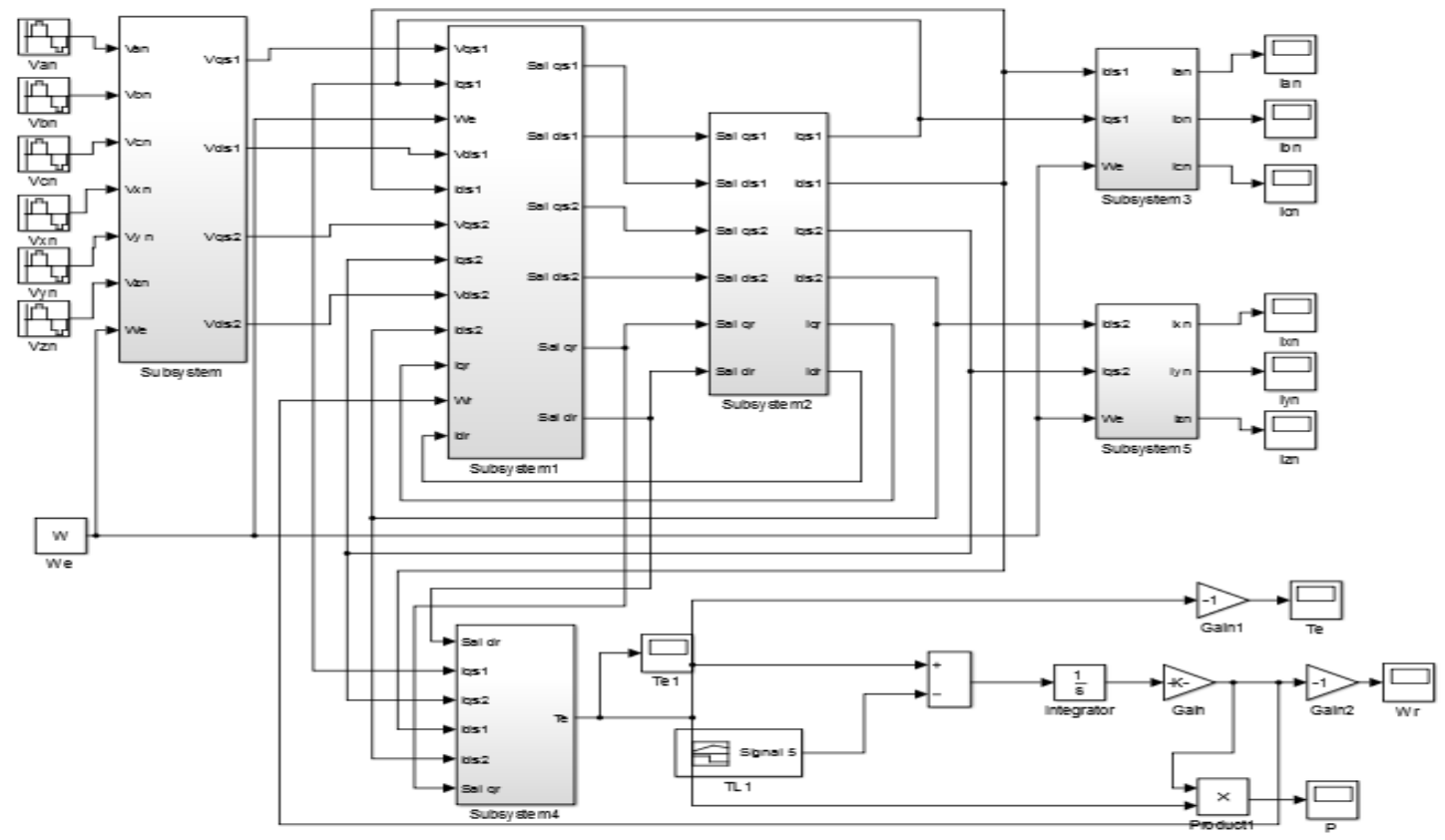

Fig.3.Simulation of six-phase induction machine in motoring mode with direct AC start up 


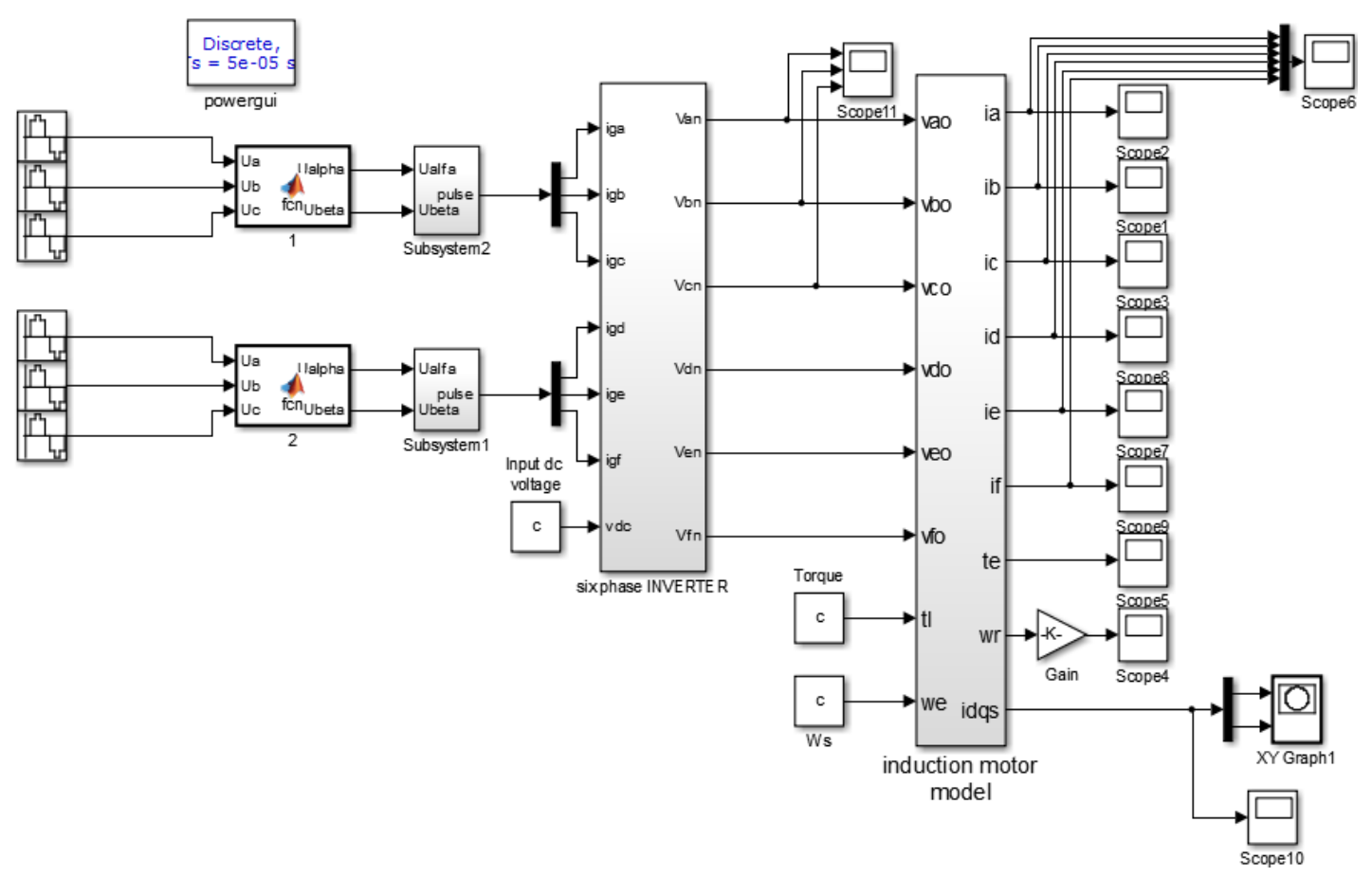

Fig.4.Simulink of six-phase induction machine in motoring mode being fed with an inverter

\section{1)No load condition}

To analyze the performance behaviour of the six-phase induction machine operating in motoring mode the simulation model of the above mentioned two models were implemented.The current, speed and torque characteristics of the machine during no-load when operated by direct AC supply is shown in Fig.5. Fig.6 shows the torque, current and the speed characteristics of the machine during no-load when operated by a sixphase inverter connected at the input side of the machine.

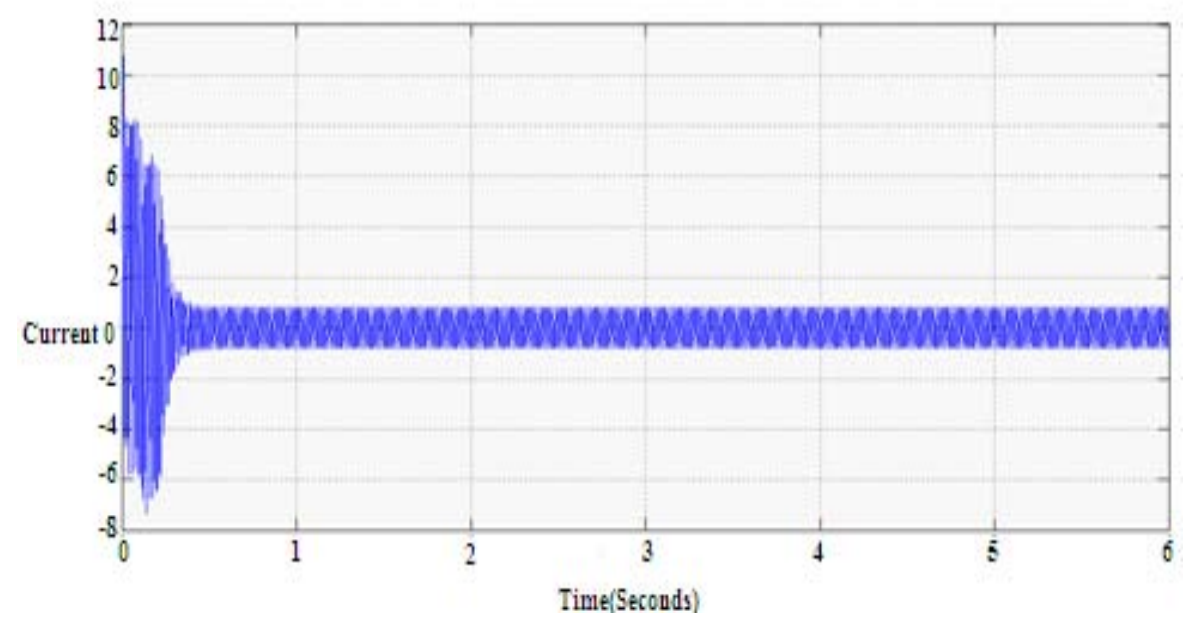



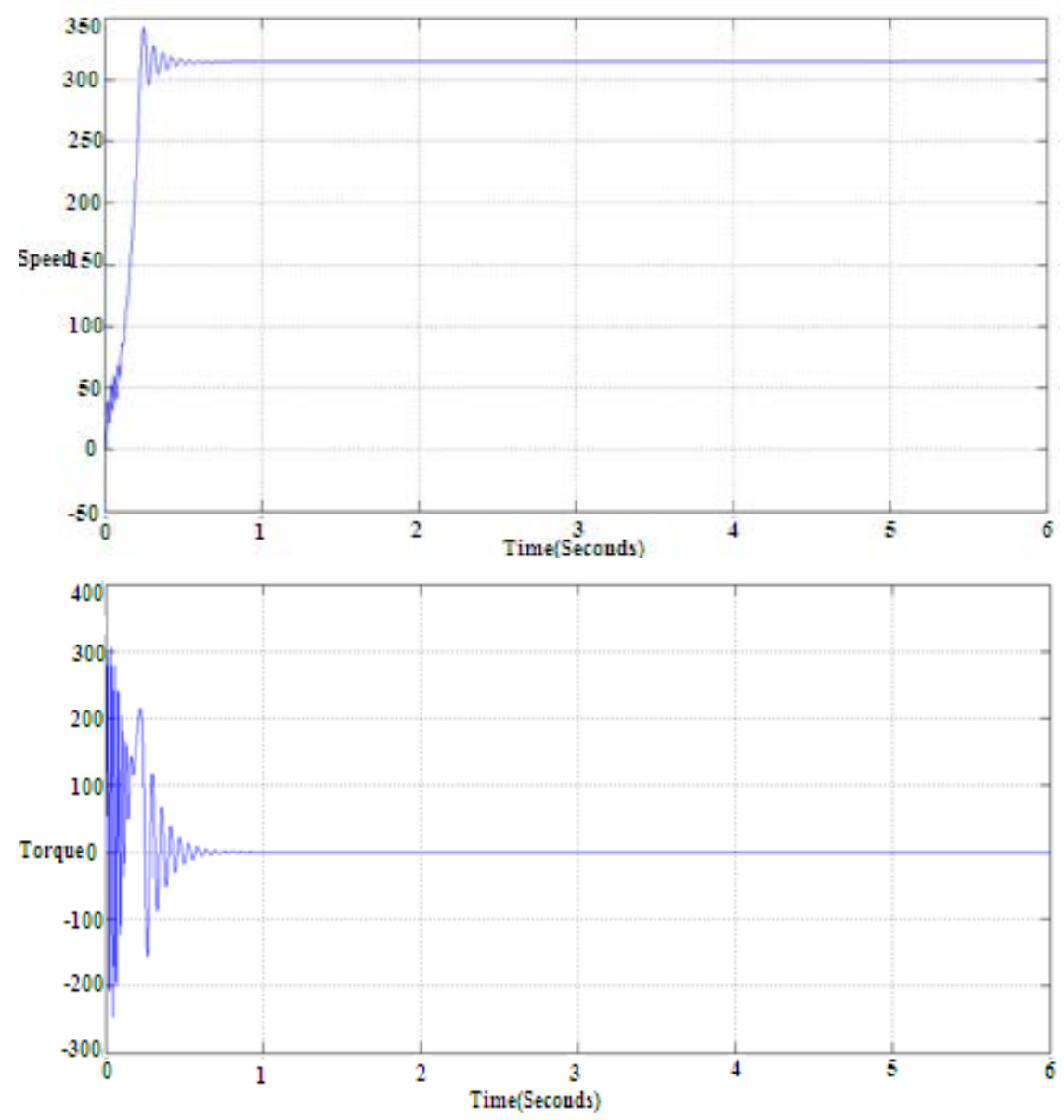

Fig.5. Current, Speed \& Torque characteristics of a direct AC fed six-phase induction machine in motoring mode
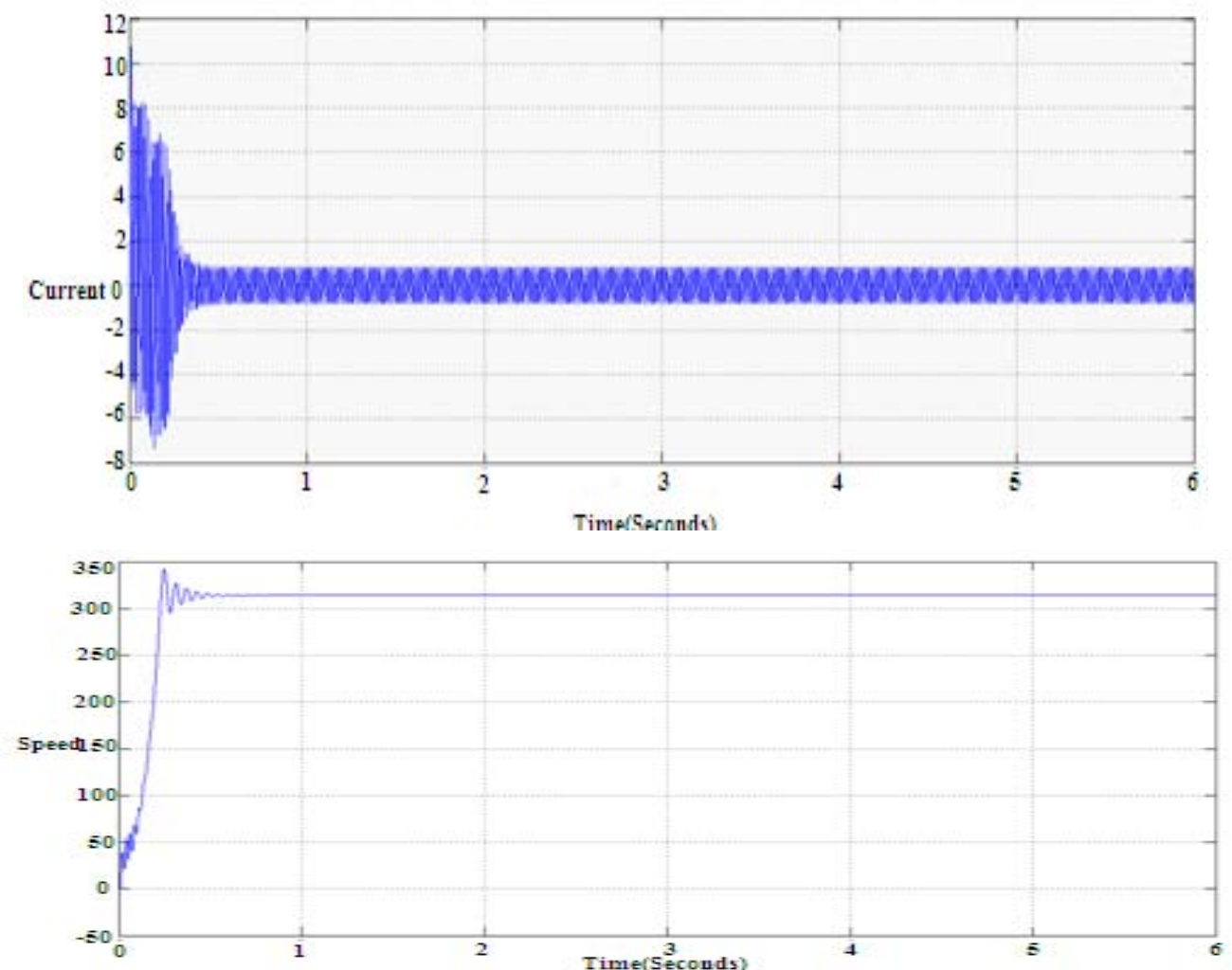

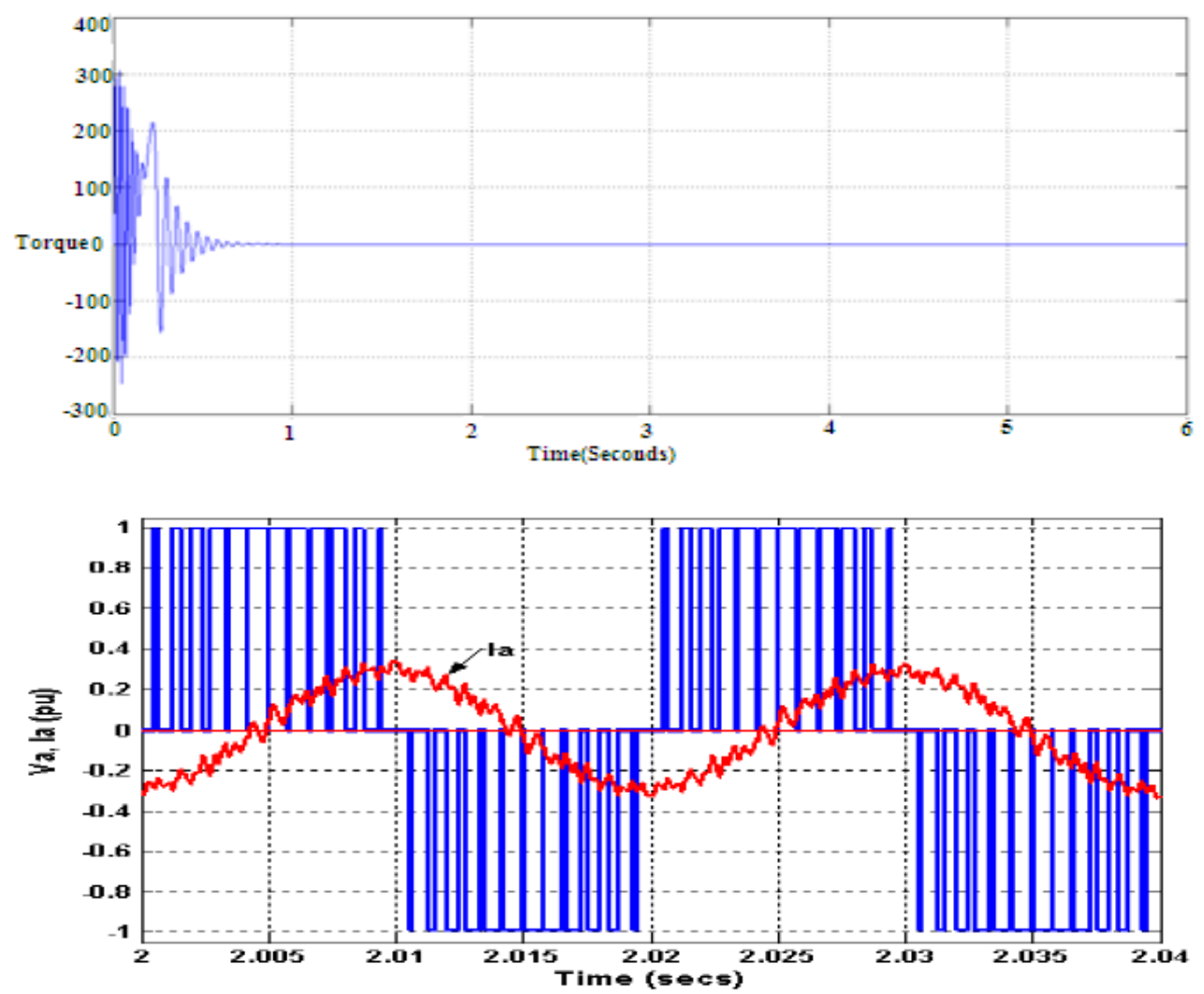

Fig.6. Current, Speed, Torque and inverter voltage of an inverter fed six-phase induction machine in motoring mode

\section{2) During loading condition}

During transient period high torque and speed oscillations are observed as shown in Fig.7. Steady state no-load torque is zero $\mathrm{Nm}$. A load torque of $10 \mathrm{Nm}$ is applied to the motor at 03 seconds. Transient period lasts up to $0.305 \mathrm{sec}$. No load speed is $314.15 \mathrm{rad} / \mathrm{sec}$. Rotor speed at load condition is $299.46 \mathrm{rad} / \mathrm{sec}$.
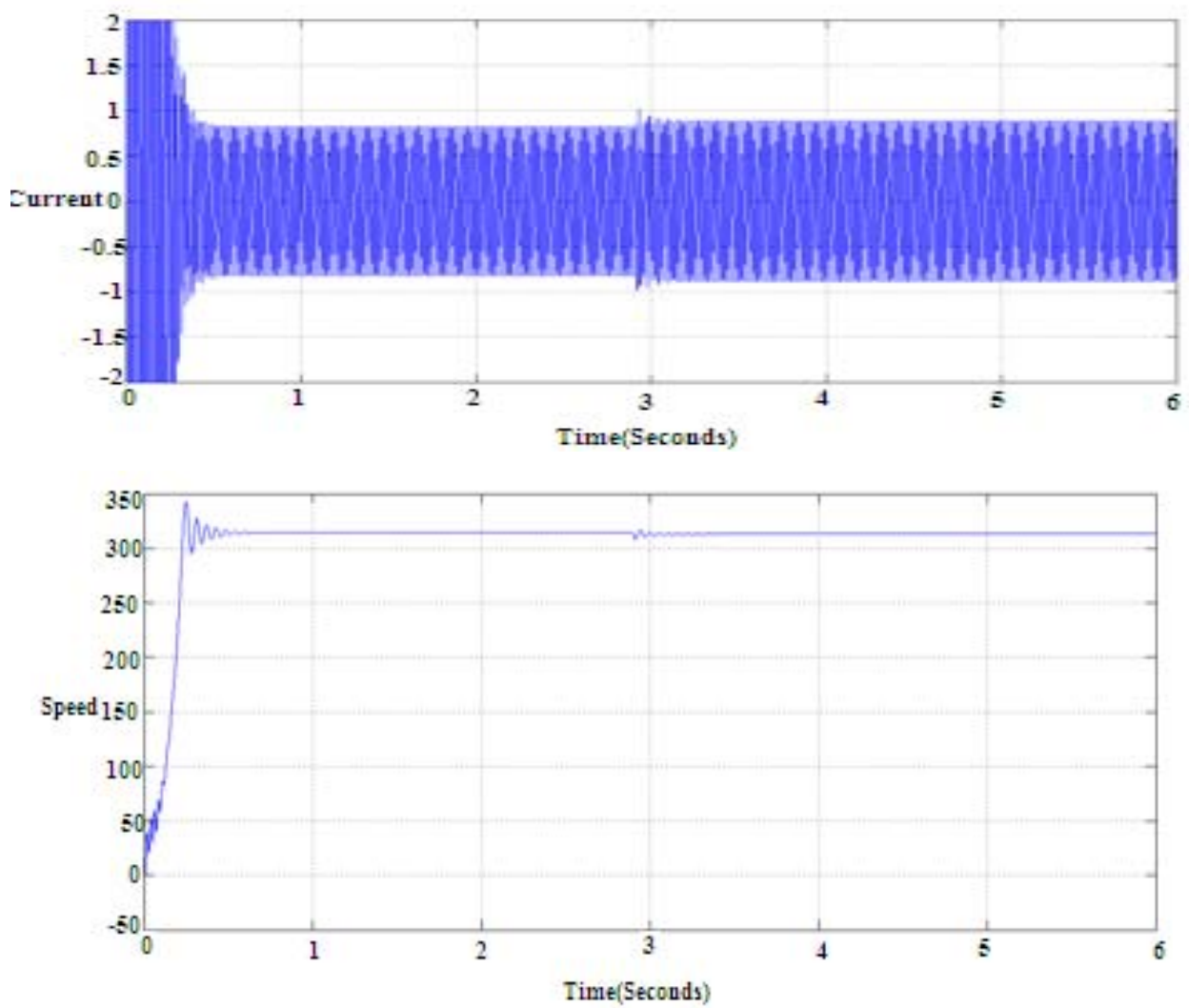


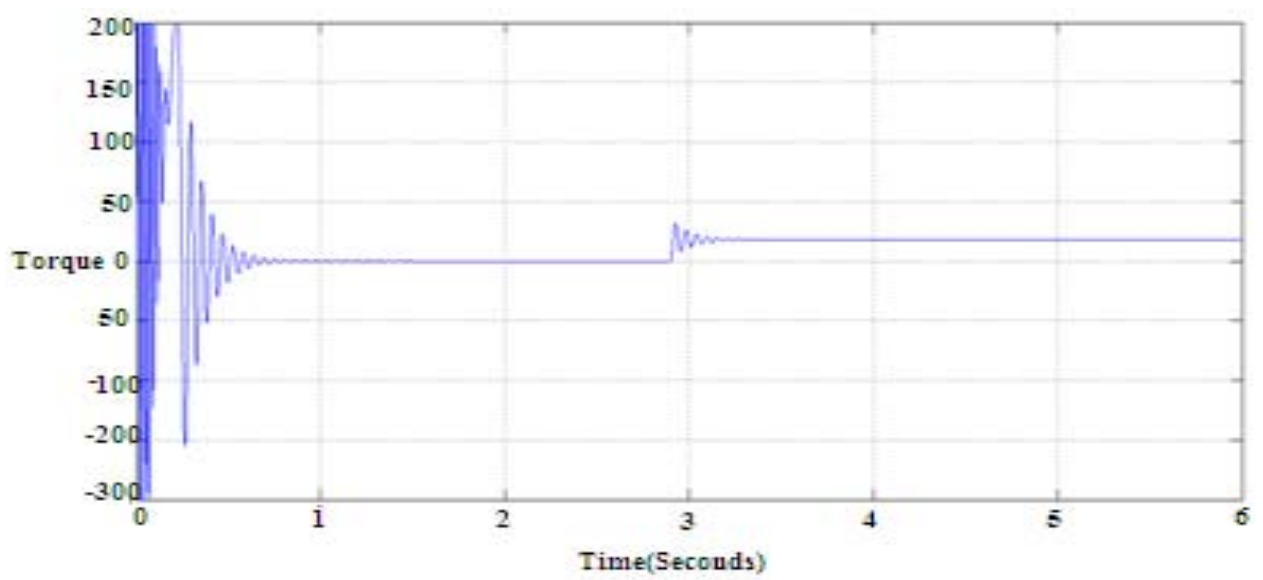

Fig.7. Current, Speed \& Torque characteristics of the machine undergoing transient period

(B)Six-phase induction machine operating in generating mode

Simulation model of an induction generator operating in six-phase mode is implemented using MATLAB/Simulink environment as shown in Fig.8.The simulations were carried out when the SEIG operating in multi-phase mode is subjected to no-load condition, when the machine is subjected to resistive-inductive load respectively.

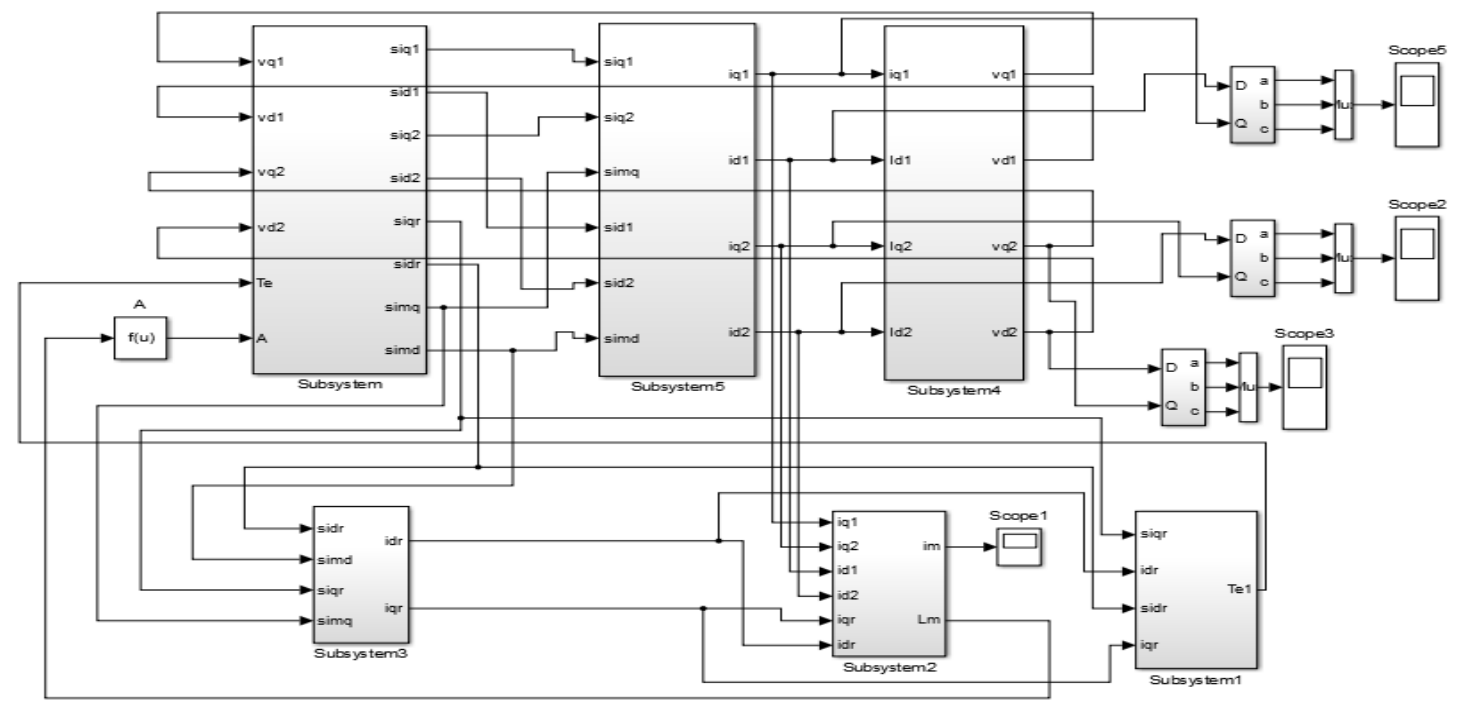

Fig.8. Simulink implementation of six-phase induction machine operating in generating mode
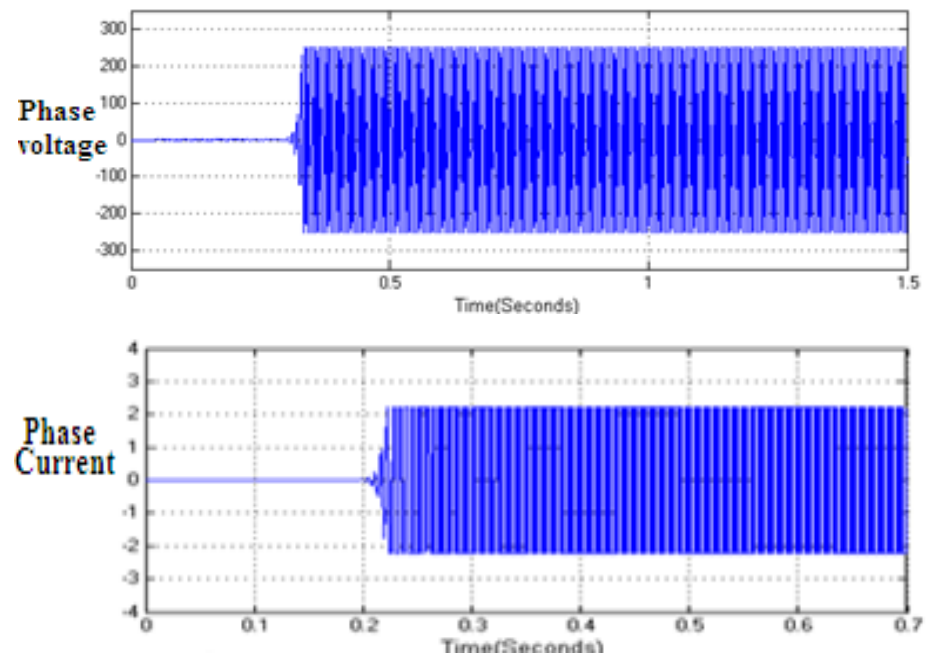

Fig.9.Voltage and current waveforms multi-phase induction machine opearing in generating mode during no-load condition 
1)Voltage and current characteristics of multi-phase induction machine operating in generating mode during no-load condition

The simulated analytical voltage characteristics during no-load are shown in the above Fig.9.The value of the capacitance connected for excitation is $90 \mu \mathrm{F}$ at rated speed of $1500 \mathrm{rpm}$. The voltage across the terminals and current rise from small voltages and amperes until steady state is attained. The machine attains its steady state values at 240 volts approximately during no-load period

2)Voltage and current characteristics of multi-phase induction machine operating in generating mode when resistively loaded

Voltage and current waveform of six phase self-excited induction generator when connected to a resistive load of $200 \Omega$ is shown in the Fig. 10 \& 11 respectively. The resistive load is applied to the machine as a time instant of 0.3 seconds.A decrease in voltage is seen in the self-excited induction generator operating in six phase mode which is nearly to 200 volts which reduces the current across the capacitor, which reduces voltage across self-excited induction generator operating in six phase mode.

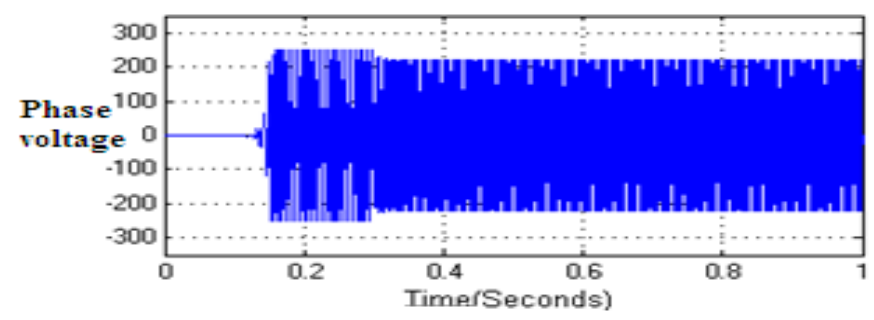

Fig.10. Phase voltage when the machine is subjected to resistive load

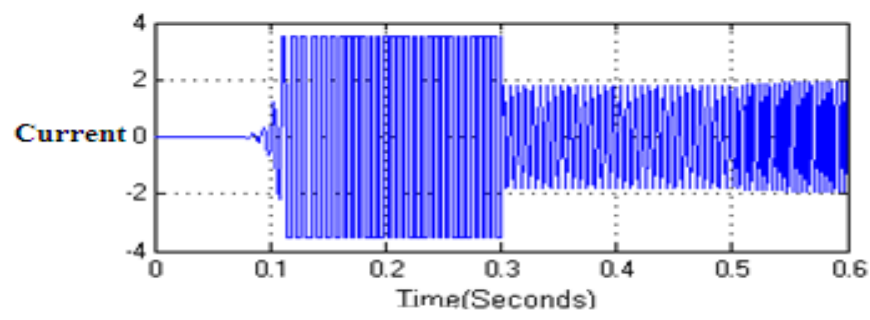

Fig.11. Phase current when the machine is subjected to resistive load

3)Voltage and current characteristics of multi-phase induction machine operating in generating mode when resistively-inductively loaded.

The load test is conducted with balanced resistive-inductive load consisting $200 \Omega$ resistance and inductance $500 \mathrm{mH}$. The load is applied at a time instant of 0.5 seconds. The voltage and current waveforms are shown in Fig.12 \& 13 respectively. The results show that the terminal voltage and current attain their new steady-state operation with reduction of output voltage.

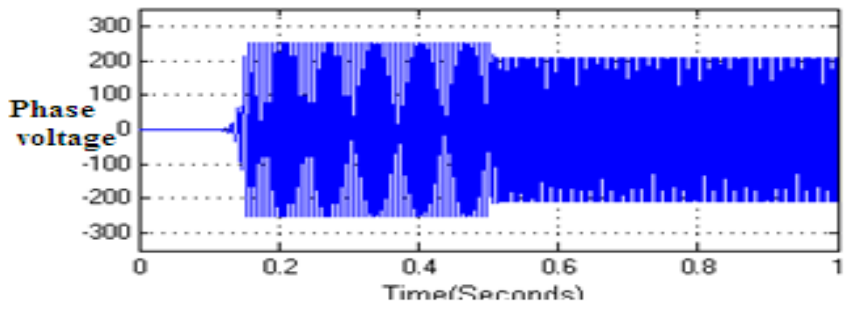

Fig.12. Phase voltage when the machine is subjected to resistive-inductive load

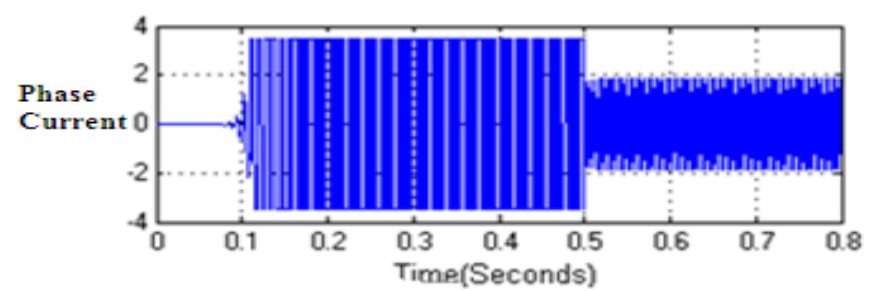

Fig.13. Phase current when the machine is subjected to resistive-inductive load 


\section{VI.CONCLUSION}

The simulation model of a multi-phase induction machine operating in motoring and generating have been implemented in this paper for analyzing the performance of the machine. When induction machine is operating in motoring mode the result shows high performance, lesser current per phase, torque generated is smooth and the ripples generated are negligible. As the phase currents are not high and efficiency is good this motor is suitable for higher power applications. In the analysis it is observed that when the six-phase machine when operating as a generator gives higher reliability as compared with its three phase counterpart and can feed two separate loads connected across two winding sets which has the advantage that if a fault occurs in one set it will not affect the other set, hence it remains in healthy condition.

\section{APPENDIX}

The parameters of the six-phase induction machine used are as follows:

$\mathrm{Lm}=0.4, \mathrm{Ls}=0.006, \mathrm{Lr}=0.0095, \mathrm{Llm}=0.04, \mathrm{Rs}=4, \mathrm{Rr}=2.2, \mathrm{Jr}=0.03, \mathrm{~W}=2 * \mathrm{pi} * 50$

\section{REFERENCES}

[1] E. A. Klingshirn,"High phase order induction motors-Part I: experimental results," IEEE Trans. Power Applications Systems, vol. 102, pp. 54-591, 1983

[2] E.A. Kligshirn,"High phase order induction motors-Part-II-Experimental results", IEEE Trans. PAS-102 (1) (1983) 54-59.

[3] Singh, G.K.: 'Multi-phase induction machine drive research - a survey', Electrical. Power Syst. Research, 2002, 61, pp. 139-147

[4] V. Pant, G.K. Singh and S.N. Singh,”Modeling Of A Multi-Phase Induction Machine Under Fault Condition”, IEEE International Conference PEDS'99,vol.1, pp.92-97,July1999

[5] J.M. Apsley and S. Williamson,"Analysis of Multi-Phase Induction Machines with Winding Faults", IEEE International Conference on Electric Machines and Drives, pp.249-255, May2005

[6] Gerard Aroquiadassou, Humberto Henao, Gerard-Andre Capolino, 'Experimental Analysis Of The dqo Stator Current Component Spectra Of A 42V Fault-Tolerant Six- Phase Induction Machine Drive With Opened Stator Phases ', IEEE International Symposium SDEMPED,pp.52-57, September2007

[7] Singh G.K. 'Self excited induction generator research-a survey 'Electrical Power system Research.vol 69, pp-107-114, 2004

[8] Ridwan Gunawan, Feri Yusivar, Budiyanto Budiyanto, 'The self excited induction generator with observation magnetizing characteristic in the air gap ', International Journal of Power Electronics and Drive Systems (IJPEDS)Vol 5 No 3, 2015 pages 355-365

[9] Kopella Sai Teja, R.B.R. Prakash, 'Power quality improvement using custom power devices in squirrel cage induction generator wind farm to weak grid connection by using neurofuzzy control', International Journal of Power Electronics and Drive Systems (IJPEDS), Vol 5 No 4, 2015 pages 477-485

[10] Jinyong Yu, Kai Zhang, Lingshun LIU, Shutuan Zhang, Jing Jiang, 'Optimal analysis on reactive capacity of control winding for dual statorwinding induction generator', TELKOMNIKA Indonesian Journal of Electrical Engineering Vol 12 No 4, 2014 pages 26222627

[11] Singh, G. K., Yadav, K. B., and Saini, R. P., "Modeling and analysis of multi-phase (six-phase) Self-Excited induction generator," Proc. IEEE Conf. The Eighth International Conference on Electrical Machines and Systems, ICEMS'05, Vol. 3, pp.1922-27, September 27-29, 2005

[12] Singh, G. K., Yadav, K. B., and Saini, R. P., "Analysis of a saturated multi-phase (six-phase) self-excited induction generator," International Journal of Emerging Electric Power Systems, Vol. 7, pp.1- 23, 2006.

\section{AUTHOR PROFILE}

Alok Kumar Mohanty has completed his Bachelors degree in Electrical Engineering under BPUT,Odisha,India in the year 2005.He has completed his Masters in Electrical Engineering in 2010 from National Institute of Technology, Durgapur,India.Currently he is a Research scholar in the Department of Electrical and Electronics Enginnering in National Institute of Technology,Jamshedpur,India.His field of interest include Electrical Machines and Drives and their applications.

$\mathrm{K} \mathrm{B}$ Yadav has completed his $\mathrm{PhD}$ degree in Electrical Engineering from Indian Institute of Technology,Roorkee, India.Currently he is working as an Associate Professor in the the Department of Electrical and Electronics Enginnering in National Institute of Technology, Jamshedpur,India. His field of interest include Electrical Machines and Drives. 